\title{
Discharge coefficient equation to calculate the leakage from pipe networks
}

\author{
Ömer EKMEKCİĞLU ${ }^{1 *}$, Eyyup Ensar BAŞAKIN ${ }^{1}$, Mehmet ÖZGER ${ }^{1 *}$
}

\begin{abstract}
With the increasing of urbanization, water distribution networks play an important role in human life and the effective use of water resources. Therefore, studies have been made for the optimization of water distribution networks in some fields such as pressure management and leakage control. In this context, the discharge coefficient, which is one of the components of the hydraulic calculations, is a very significant parameter in calculating the losses. In this study, a new equation has been proposed to calculate the discharge coefficient. Computer simulations were done by using ANSYS Fluent and discharge coefficient values were determined for round holes. Firstly, the model validated with theoretical Toricelli (orifice) equation and then, the model was run for number of scenarios according to various internal pressure and hole areas. The model results were formulated by means of regression equations. To satisfy the dimensional homogeneity, the ratio of the hole area to the pipe crosssectional area, area ratio (r), and the ratio of the internal pressure to the external pressure, pressure ratio (p), were used. In this study, easy to use discharge coefficient equation was proposed to calculate the leakage losses in water distribution networks. With the help of this equation, the discharge coefficient can be calculated precisely for different pressure values and leakage areas rather thantaken as a constant value. Thus, the calculation of the leakage flow rate will be more accurate. Furthermore, it is concluded that the dicharge coefficient varies between 0.65 and 0.72 . There is also inverse realtionship between discharge coefficient and pressure and discharge coefficient and leakage area.
\end{abstract}

Keywords: water distribution network, discharge coefficient, leakage, orifice

\footnotetext{
${ }_{1}^{1}$ Ömer EKMEKCİOĞLU (Orcid ID: 0000-0002-7144-2338), Eyyup Ensar BAŞAKIN (Orcid ID: 0000-0002-9045-5302), Mehmet ÖZGER (Orcid ID: 0000-0001-9812-9918), Hydraulics Division, Civil Engineering Department, Istanbul Technical University, Maslak 34469, Istanbul, Turkey

*Sorumlu Yazar/Corresponding Author: Ömer EKMEKCIOĞLU, e-mail: omer.ekmekcioglu@itu.edu.tr

* Bu çalışma Ömer EKMEKCİOĞLU’ nun Yüksek Lisans tezinden üretilmiştir.
} 


\section{INTRODUCTION}

One of the most crucial point for the efficient use of water resources is to avoid the loss of leakage in water distribution networks. In this respect, with the emergence of leakage problems, the researchers focused on behaviors of the leaks and the reduction of leakage flowrates due to the leaks. Particularly, studies on pressure management have gained popularity (Sturm and Thornton, 2015; Thornton and Lambert, 2007; Xu et al., 2014; Fontana et al., 2017; Lydon et al., 2017; Samir et al., 2017; Monsef et al., 2018). As a result of the studies on pressure management, a serious improvements have been observed in the service capacity of the water distribution networks. While making progress with these studies, studies have been carried out in order to put the problem on a correct basis. Consequently, the orifice equation examined in detail for the calculation of leakage flow rate.

Toricelli equation, i.e. orifice equation, is the basis of the studies that have been carried out in the leakage in water distribution networks. Toricelli equation represents to the relationship between pressure and leakage flow rate which is based on the principle of conservation of energy. The pipe leaks physically coincide with the orifice equation, since they display orifice characteristics.

According to the orifice equation and the relationship between pressure and loss due to leakage can expressed as follows:

$$
Q=C_{d} \times A \times \sqrt{2 g h}
$$

where, $Q$ is the leakage flow rate, $\mathrm{C}_{\mathrm{d}}$ is the discharge coefficient, $\mathrm{A}$ is the leakage area, $\mathrm{g}$ is the acceleration due to the gravity and $\mathrm{h}$ represents the pressure head.

By considering that the orifice equation can also wrote as (May, 1994):

$$
Q_{L}=C \times h^{N 1}
$$

in which $\mathrm{C}$ is the leakage coefficient and it consists of $\mathrm{C}_{\mathrm{d}}, \mathrm{A}$ and $(2 \mathrm{~g})^{0.5} . N 1$ denotes the leakage exponent.

Studies had been carried out about the leakage area (May, 1994; Cassa et al., 2010; Cassa and Van Zyl, 2013; Ssozi et al., 2015; Fox et al., 2016\&2017; De Marchis et al., 2016; Van Zyl and Malde, 2017; Van Zyl et al., 2017, Kabaasha et al., 2018; Nsanzubuhoro et al., 2017; Butterfield et al., 2018) and studies about leakage exponent (Germanopoulos, 1985; Walski et al., 2006\&2009; Greyvenstein and J. E. van Zyl, 2007; Van Zyl and Clayton, 2017) made contribution to better understanding of the leakage behavior and leakage flowrate.

The pressure-leakage relationship in water distribution networks is not only the topic that studies based on, there is also another topic which is emphasized by various researchers, named as discharge coefficient. Altoughthe discharge coefficient is considered as the least effective parameter in the calculation of leakage flowrate according to many researchers, it is very effective when taken account large-scaled.

Some of the researchers have assumed that discharge coefficient should be accepted as a constant, while some of them thought that it may be variable depending on some other parameters. Cassa et al. (2010) considered the discharge coefficient as constant, 0.67. Schwaller and van Zyl (2014) showed that the discharge coefficients in a water distribution network would take values between 0.5 and 0.8 , averagely 0.65 , with a presumption of normal distribution. For individual leaks, Lambert (2001) stated that the assumption of the constant discharge coefficient is not valid for all flow regimes. Therefore, the discharge coefficient depends on the laminar, transition and turbulent regime, so the Reynolds number. 
Furthermore, for the orifice problem for incompressible fluids, it is indicated that the discharge coefficient is a function of the hole geometry, area ratio (ratio of orifice area to pipe cross-sectional area) and Reynolds number (Idelchik, 2003). In another study that examined the relationship between pressure and leakage flowrates, Schwaller and van Zyl (2014) stated that the discharge coefficient is a function of the shape of the hole, the material of the pipe, the curvature of the pipe and various physical parameters such as pressure. They also stated that the discharge coefficient values in the cracks occurring under normal conditions are between 0.5 and 0.8 , while only $10 \%$ of them is greater than 0.7 . In this study, a study was carried out on the basis that the discharge coefficient depends on a number of parameters and can be written as a function of those parameters. In the numerical analysis, it was observed that the discharge coefficient varies with leakage area and pressure.

In this study, a research has been carried out on the fact that the discharge coefficient depends on a number of parameters and can be written as a function number of parameters. Through numerical analysis, it was observed that the discharge coefficient varies with leakage hole area and pressure. Accordingly, an equation has been proposed to calculate the discharge coefficient related to these variables. Therefore, the purpose of this study to formulate discharge coefficient based on the leakage area and pressure using a numerical model.

\section{MATERIALS AND METHODS}

\section{Numerical Model}

ANSYS Fluent software was used in the numerical model. ANSYS Fluent, which can model CFD models quickly and cost-effectively, including various complex and large systems such as free surfaces, multiple fluid phases, viscous and turbulent flows, uses the finite volumes method for discretization of conservation equations. In this study, a numerical analysis was made by taking $1 \mathrm{~m}$ unit length and 10 $\mathrm{cm}$ diameter pipe into consideration for the high density polyethylene (HDPE) pipe. Simulations were made by changing the hole area under different pressure conditions for round hole (Fig. 1). Different discharge coefficient values obtained as a result of simulations are associated with hole area and pressure variables.

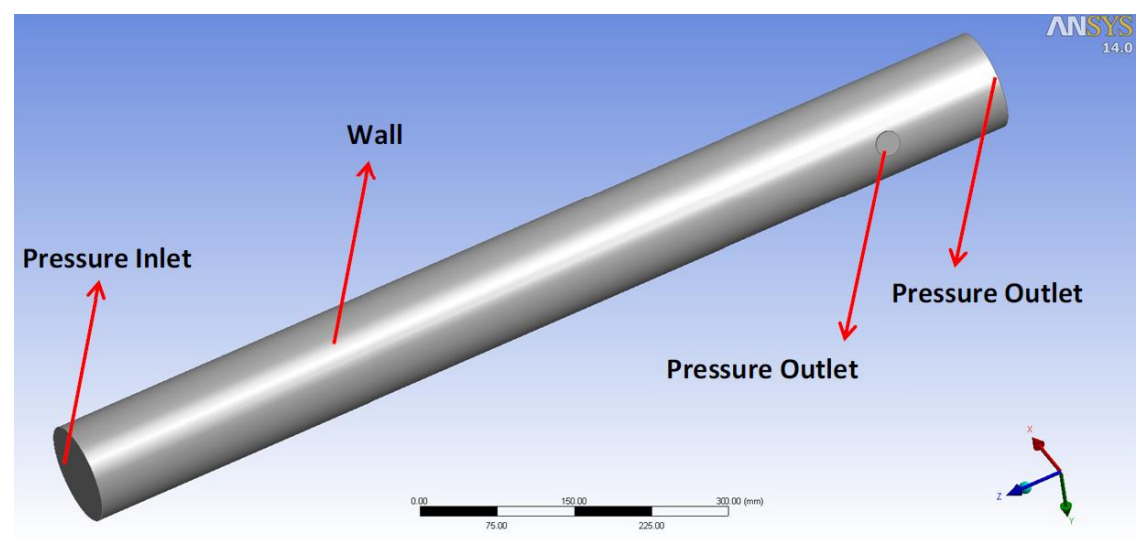

Figure 1. Model geometry.

The following assumptions were made in modeling of discharge coefficient. (1) The hole opens to the atmosphere. (2) Computations were made for the High Density Polyetylene (HDPE) pipe. (3) Pipe length was 1 meter and diameter was $10 \mathrm{~cm}$. (4) Hole area varied between $7.85 \times 10^{-5}$ and $4.92 \times 10^{-4} \mathrm{~m}^{2}$. (5) The internal pressure of the pipe ranged from 1 bar to 7 bar. The reason for emphasizing the similarity of the problem to the orifice equation is due to the similarity to the calculation of the water flow through 
a hole in a large tank. That is, there is considerable difference between the pipe diameter and the hole diameter to make the difference between the velocity values obtained from the continuity equation.

SIMPLE was used as the solution scheme, since the problem is single phase which means that there is full flow in pipe. Least Squares Cell-Based Gradient Evaluation was chosen as a gradient, this method yields more successful solutions, particularly in unstructured meshes compared to the other methods and it is less time consuming. Second order upwind scheme was chosen for the Momentum, Turbulent Kinetic Energy and Turbulent Dissipation Rate. With this scheme, higher accuracy is obtained, since the values on the cell surface are evaluated by means of the centroid cells using Taylor series expansion.

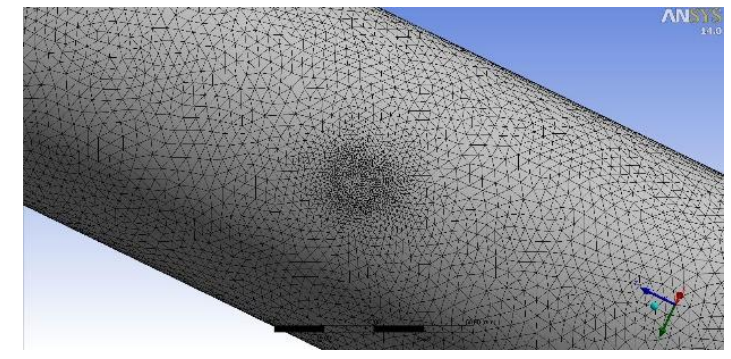

(a)

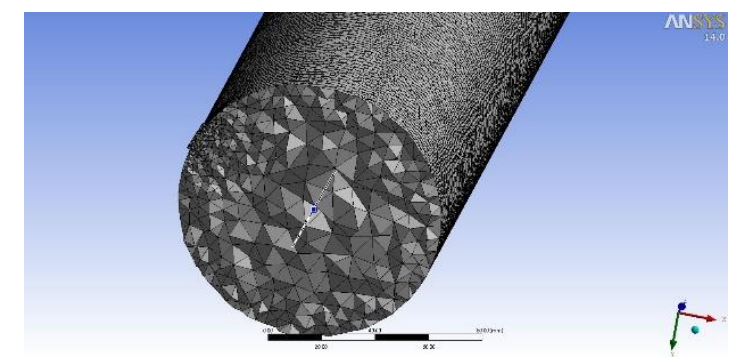

(b)

Figure 2. Mesh created with the ANSYS. a) Plan view b) Cross-section view

\section{Governing Equations}

ANSYS Fluent solves the conservation of mass and conservation of momentum in cases without heat transfer. The mass conservation equation, or continuity equation, is based on the principle of mass balance for a fluid particle. It means that rate of increase of mass in fluid element equals to net rate of flow of mass into fluid element. Continuity equation for three dimensional cartesian coordinates can be written as follows:

$$
\frac{\partial \rho}{\partial t}+\frac{\partial(\rho u)}{\partial x}+\frac{\partial(\rho v)}{\partial y}+\frac{\partial(\rho w)}{\partial z}=0
$$

in which $\rho$ is the density and $\mathrm{u}, \mathrm{v}$ and $\mathrm{w}$ represent the velocity components on $\mathrm{x}, \mathrm{y}$ and $\mathrm{z}$ directions, respectively. Yet, Eq.3 is valid for compressible flows. For incompressible flows Eq.4 can be written as:

$$
\frac{\partial u}{\partial x}+\frac{\partial v}{\partial y}+\frac{\partial w}{\partial z}=0
$$

Rate of change of momentum is associated with the sum of the forces in the control volume. It means that the rate of increase of momentum of fluid particle equals to sum of forces in fluid particle. The forces in a fluid particle are divided into two main groups: (i) Surface forces, (bii) Body forces. The surface forces include compressive forces, viscous forces and gravitational forces, while the body forces contain centrifugal forces, Coriolis forces and electromagnetic forces. Thus, the momentum equation can be written for three dimensional cartesian coordinates as follows:

$$
\begin{aligned}
& \rho \frac{D u}{D t}=\frac{\partial\left(-p+\tau_{x x}\right)}{\partial x}+\frac{\partial \tau_{y x}}{\partial y}+\frac{\partial \tau_{z x}}{\partial z}+S_{M x} \\
& \rho \frac{D v}{D t}=\frac{\partial \tau_{x y}}{\partial x}+\frac{\partial\left(-p+\tau_{y y}\right)}{\partial y}+\frac{\partial \tau_{z y}}{\partial z}+S_{M y} \\
& \rho \frac{D w}{D t}=\frac{\partial \tau_{x z}}{\partial x}+\frac{\partial \tau_{y z}}{\partial y}+\frac{\partial\left(-p+\tau_{z z}\right)}{\partial z}+S_{M z}
\end{aligned}
$$


where $\mathrm{p}$ is the pressure force, $\tau$ represents the shear stress and the $\mathrm{S}$ is the source term that includes all body forces which affects the control volume per unit time. D/Dt denotes the material derivative that refers to the sum of the temporal physical properties of a material element, such as temperature and momentum. In this study, standard k-epsilon turbulent model is used. Transport equations for standard k-epsilon model are given below as turbulent kinetic energy per unit mass (k) and turbulent energy dissipation rate per unit mass $(\epsilon)$ in Eq.8 and Eq.9, respectively.

$$
\begin{gathered}
\frac{\partial}{\partial t}(\rho k)+\frac{\partial}{\partial t_{i}}\left(\rho k u_{i}\right)=\frac{\partial}{\partial x_{j}}\left[\left(\mu+\frac{\mu_{t}}{\sigma_{k}}\right) \frac{\partial k}{\partial x_{j}}\right]+P_{k}+P_{b}-\rho \epsilon-Y_{M}+S_{k} \\
\frac{\partial}{\partial t}(\rho \epsilon)+\frac{\partial}{\partial t_{i}}\left(\rho \epsilon u_{i}\right)=\frac{\partial}{\partial x_{j}}\left[\left(\mu+\frac{\mu_{t}}{\sigma_{\epsilon}}\right) \frac{\partial \epsilon}{\partial x_{j}}\right]+C_{1 \epsilon} \frac{\epsilon}{k}\left(P_{k}+C_{3 \epsilon} P_{b}\right)-C_{2 \epsilon} \rho \frac{\epsilon^{2}}{k}+S_{\epsilon}
\end{gathered}
$$

where, $\mathrm{k}$ is the turbulent kinetic energy, $\mathrm{u}_{\mathrm{i}}$ represents velocity component in corresponding direction, $\mathrm{P}_{\mathrm{k}}$ is the generation of turbulence kinetic energy due to the mean velocity gradients, $\mathrm{P}_{\mathrm{b}}$ represents the generation of turbulence kinetic energy due to buoyancy and $\mu_{t}$ is the turbulence(eddy) viscosity which is calculated as:

$$
\mu_{t}=\rho C_{\mu} \frac{k^{2}}{\epsilon}
$$

Turbulent Prandtl numbers for $\mathrm{k}$ and $\epsilon: \sigma_{\mathrm{k}}, \sigma_{\epsilon}$ and $\mathrm{C}_{1 \epsilon}, \mathrm{C}_{2 \epsilon}$ are constant values that are determined at the end of a great deal of iterations as 1.0, 1.3, 1.44, 1.92, respectively. $\mathrm{S}$ is the modulus of the mean rate-of-strain tensor and define as:

$$
S \equiv \sqrt{2 S_{i j} S_{i j}}
$$

\section{Model Validation}

In numerical simulations, the variation of leakage flow rate was examined according to pressure. For this purpose, different pressure values between 1 and 7 bar were applied to a pipe with fixed length and diameter and leakage flow rate values were obtained by Fluent at the end of each model simulation. Firstly, the results of the model were obtained for all analyzes by using the $1.75 \mathrm{~cm}$ diameter round hole and $10 \mathrm{~cm}$ diameter pipe (Fig. 1), then the results compared with the orifice equation in order to validate the model.

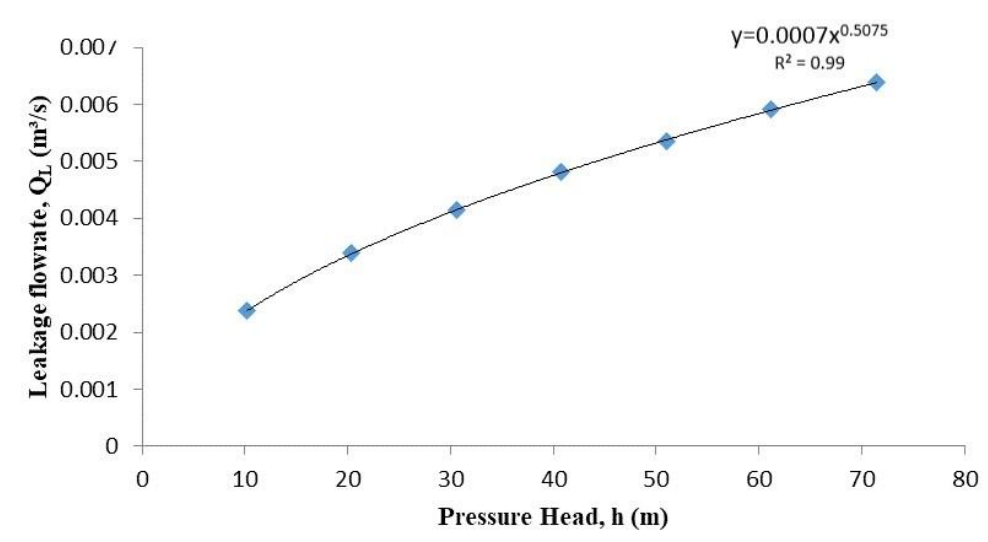

Figure 3. The Pressure-Leakage flowreate relationship. 
There is an exponential relationship between pressure head and leakage flowrate (Fig. 3). The

$$
a x^{b}
$$

regression equation of the relationship can be identified as follows:

in which $a$ represents the leakage coefficient in orifice equation and $\mathrm{b}$ denotes leakage exponent. The regression equation given on the graph and the Table 1 reveals that the leakage exponent is close to 0.5 as stated in the literature.

Table 1. Model validation results.

\begin{tabular}{cccc}
\hline Geometry & Diameter $(\mathbf{c m})$ & Equation & $\mathbf{R}^{\mathbf{2}}$ \\
\hline Round & 1.75 & $\mathrm{y}=0.0007 \mathrm{x}^{0.5075}$ & $\mathrm{R}^{2}=0.99$ \\
Round & 2 & $\mathrm{y}=0.0013 \mathrm{x}^{0.5071}$ & $\mathrm{R}^{2}=0.99$ \\
\hline
\end{tabular}

Secondly, a different fixed hole diameter $(2 \mathrm{~cm})$ was considered in the model and the analysis were repeated for all aforementioned conditions. Results of this scenario revealed that there are changes in the leakage coefficient when it is compared with first scenario. The leakage coefficient was $7 \times 10^{-4}$ in the first case (Table 1, 1st row), while it was observed as $13 \times 10^{-4}$ for the second case (Table 1, 2nd row). Leakage coefficient includes constant terms such as $(2 \mathrm{~g})^{0.5}$ and hole diameter as well as $\mathrm{C}_{\mathrm{d}}$, discharge coefficient. It is concluded that the discharge coefficient varies with changing conditions such as hole area and pressure. Therefore, unlike the fact that the discharge coefficient is a constant, it has been concluded that it varies depending on the hole area and pressure.

\section{RESULTS AND DISCUSSION}

After the establishment of the model and validation by Toricelli (orifice) equation, the results were attained according to different performed scenarios on same model. In this context, firstly, the change in the discharge coefficient with the pressure variation was examined while the area of the round hole was kept constant. The flow rate values are obtained by FLEUNT simulations and internal pressure of pipe and leak areas are known. Thus, discharge coefficient values were calculated by replacing the known values in the orifice equation. It is observed that the discharge coefficient decreases when the pressure increases (Fig. 4). It is symbolicly shown as the linear relationship in Fig. 4 in order to demonstrate the inverse relationship between to variable.

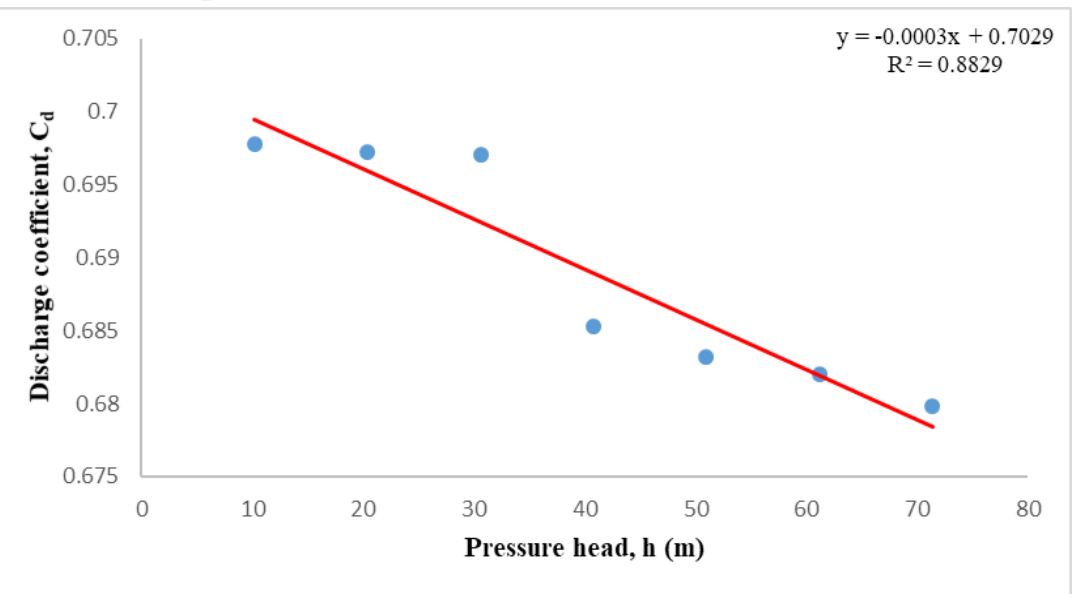

Figure 4. Variation of discharge coefficient with respect to pressure head.

Secondly, pressure was kept constant and the variation of the discharge coefficient with hole area was investigated. As a result of the simulations, it is found that the discharge coefficient changes inversely with the hole area under a constant pressure boundary condition (Fig. 5). 


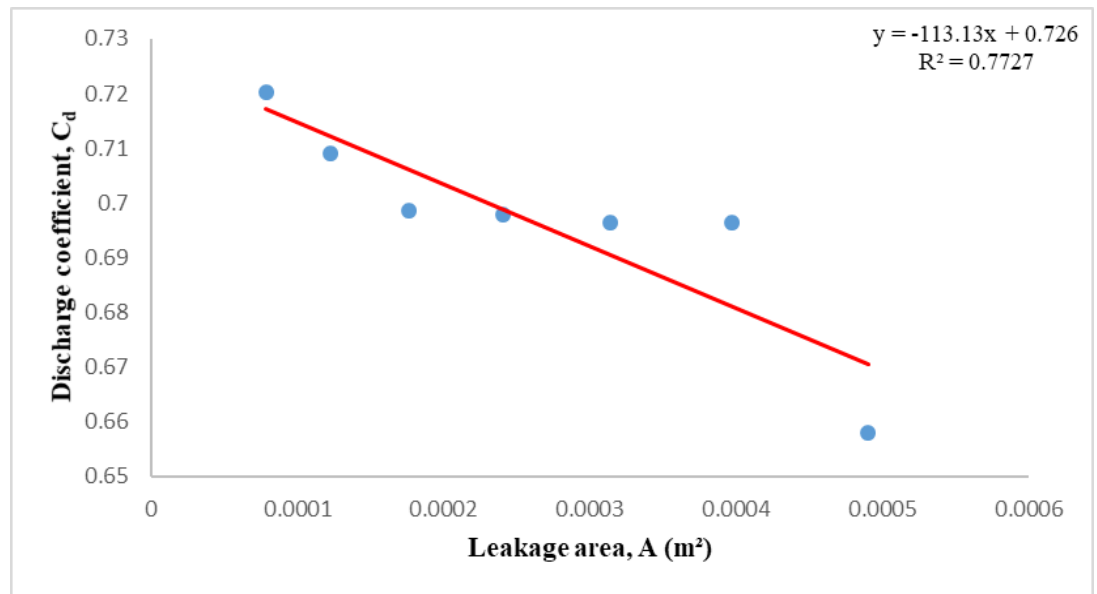

Figure 5. Variation of discharge coefficient with respect to leakage area.

As seen in Fig. 4 and Fig. 5, discharge coefficient varies between 0.65 and 0.72 . The results obtained in this study coincide with the studies in the literature (Table 2). It will be well directed to obtain a function on behalf of the discharge coefficient instead of taking as an average value. In addition, as seen in Fig. 5, the range of discharge coefficient values which is obtained by changing the hole area is greater than the range result from the pressure variation.

Based on these results, it was decided to choose the independent variables as dimensionless since the discharge coefficient is a dimensionless parameter.

Table 2. Comparison of the calculated discharge coefficient values with the studies in the literature.

\section{Reference}

Lea (1908)

Lambert (2001)

Idelchik (2003)

Cassa et al. (2010)

Schwaller and vanZyl (2014)

Schwaller et al.(2015)

Fox et al. (2016)

Current study

\section{Discharge coefficient values}

0.6
0.75
0.97
0.67
0.65
0.65
$0.64-0.75$
$0.65-0.72$

For this purpose, the dimensionless area, $r$, giving the ratio of the hole area and the pipe crosssectional area and the dimensionless pressure which is the ratio of the internal pressure to the external pressure, p, was used to generate the equation (Eq. 13).

$$
r=\frac{A_{\text {Leakage }}}{A_{\text {Pipe }}} ; p=\frac{P_{i}}{P_{e}}
$$

in which $\mathrm{A}_{\text {Leakage }}$ is the hole area, $\mathrm{A}_{\text {pipe }}$ is the pipe cross section area and $\mathrm{P}_{\mathrm{i}}, \mathrm{P}_{\mathrm{e}}$ are the internal pressure and external pressure, respectively.

Thus, Eq. 14 can be obtained as follows:

$$
\mathrm{C}_{d}=f\left(\frac{A_{\text {Leakage }}}{A_{\text {Pipe }}} ; \frac{P_{i}}{P_{e}}\right)=f(r ; p)
$$


To obtain a general equation for discharge coefficient, seven different leakage areas and seven different pressure values were used to conduct 49 simulations. As a result, linear regression analysis was used to find the equation that could be obtained by using the data of the simulation results. In the regression equation, $\mathrm{r}, \mathrm{r}^{2}, \mathrm{r}^{3}, \mathrm{p}, \mathrm{p}^{2}, \mathrm{p}^{0.5}$ were used as input. In addition, the best matched equation was decided upon by the evaluation made according to various performance criteria, such as root mean square error (RMSE), mean absolute percentage error (MAPE) and determination coefficient $\left(\mathrm{R}^{2}\right)$. The results of the calculated performance criterias are presented in Table 3. As a result of different analysis to obtain best matched equation, Eq. 15 was obtained.

$$
C_{d}=0.396 \times r-23.749 \times r^{2}+92.264 \times r^{3}+0.0026 \times p+0.6987
$$

Table 3. Performance of the equations derived for the optimum discharge coefficient function.

\begin{tabular}{cccc}
\hline Independent Variable & RMSE & MAPE (\%) & $\mathbf{R}^{\mathbf{2}}$ \\
\hline $\mathrm{r}, \mathrm{r}^{2}, \mathrm{r}^{3}, \mathrm{p}$ & 0.073390936 & 0.799844685 & 0.9321 \\
\hline
\end{tabular}

The equations were derived by using the least squares method. The least squares method is a parametric method and some conditions must be fulfilled for statistical significance. One of these conditions is that the coefficients of equation are significantly different from zero and it is decided by taking into consideration of $p$ values. In this study, each coefficient was found smaller than 0.05 at $\% 95$ confidence interval, as a result of the tests performed. Thus, it demonstrated that all coefficients are significantly different from zero. Furhermore, it can be concluded that the proposed equation is not only offers practical to use, but also provides accurate results with low number of variables.

\section{CONCLUSION}

A numerical model was developed by using the finite volume method to investigate the discharge coefficient under different scenerios. The factors that have the most effect on this value have been determined and it has been found in the simulations that the discharge coefficient is a function of the leakage area, pressure and hole geometry. A practical equation was proposed to calculate the discharge coefficient according to the hole area and pressure.

In the proposed equation, hole area and pressure head made dimensionless to satisfy dimensional homogeneity. The first dimensionless number is obtained as area ratio, which represents the ratio of the leakage area to the pipe cross-sectional area (r), while the second is the pressure ratio (p), which describes the ratio of the pipe internal pressure to the external pressure.

In this study, it is suggested that the discharge coefficient can be calculated with the help of a simple equation and this approach will give more accurate results than the calculations made assuming that the discharge coefficient is constant. In addition, a contribution has been made to the literature to enable better understanding of losses, which are a major problem in water distribution networks.

The results of the study are listed below:

- Discharge coefficient varies between 0.65 and 0.72 for round hole.

- Expression of the proposed equation as a function of dimensionless variables is significant in terms of uniformity and practicality

- The equation obtained for discharge coefficient yielded very high accuracy according to various performance indicators.

- Instead of taking the flow coefficient as a constant in the leakage flow rate calculations, a function is obtained from the factors affecting the flow coefficient (pressure and leakage area) and the leakage flow rate calculations should be done in this way. 
In this study, hydraulically, a proposal has been made to provide a more accurate understanding of this topic, which has recently been carried out on a considerable number of studies.

\section{REFERENCES}

Butterfield JD, Meyers G, Meruane V, Collins RP, Beck SBM, 2018. Experimental investigation into techniques to predict leak shapes in water distribution systems using vibration measurements. Journal of Hydroinformatics 20 (4): 815-828.

Cassa AM, Van Zyl JE, 2013. Predicting the head-leakage slope of cracks in pipes subject to elastic deformations. Journal of Water Supply Research and Technology - AQUA 62(4), 214-223.

Cassa AM, van Zyl JE, Laubscher RF, 2010. A numerical investigation into the effect of pressure on holes and cracks in water supply pipes. Urban Water Journal 7(2), 109-120.

De Marchis M, Fontanazza CM, Freni G, Notaro V, Puleo V, 2016. Experimental evidence of leaks in elastic pipes. Water Resources Management 30(6), 2005-2019.

Fontana N, Giugni M, Glielmo L, Marini G, and Verrilli F, 2017. A Lab Prototype of Pressure Control in Water Distribution Networks. IFAC-PapersOnLine 50 (1), 15373-15378.

Fox S, Collins R, Boxall J, 2016. Experimental study exploring the interaction of structural and leakage dynamics. Journal of Hydraulic Engineering 143(2), 04016080.

Fox S, Collins R, Boxall J, 2017. Physical investigation into the significance of ground conditions on dynamic leakage behaviour. Journal of Water Supply Research and Technology 65(2), 103-115.

Germanopoulos G, 1985. A technical note on the inclusion of pressure dependent demand and leakage terms in water supply network models. Civil Engineering Systems 2(3), 171-179.

Greyvenstein B, van Zyl JE, 2007. An experimental investigation into the pressure-leakage relationship of some failed water pipes. Journal of Water Supply Research and Technology -AQUA 56(2), 117-124.

Idelchik E, 2003. Handbook of hydraulic resistance (2nd revised and enlarged edition): Washington.

Kabaasha M, Piller O, van Zyl JE, 2018. Incorporating the Modified Orifice Equation into Pipe Network Solvers for More Realistic Leakage Modeling. Journal of Hydraulic Engineering 144(2): 04017064.

Lambert AO, 2001. What do we know about pressure: leakage relationships in distribution systems? IWA Conference System Approach to Leakage Control and Water Distribution Systems Management, 1-9.

Lydon T, Coughlan P, McNabola A, 2017. Pressure management and energy recovery in water distribution networks: Development of design and selection methodologies using three pump-as-turbine case studies. Renewable Energy 114:1038-1050.

May J, 1994. Pressure dependent leakage. World Water \& Environmental Engineering. http://www.leakssuite.com/wpcontent/uploads/2016/10/JOHN-MAYSEMINAL-1994 ARTICLE4.pdf.

Monsef H, Naghashzadegan M, Farmani R, Jamali A, 2018. Pressure management in water distribution systems in order to reduce energy consumption and background leakage. Journal of Water Supply Research and Technology 67 (4): 397-403.

Nsanzubuhoro R , van Zyl JE, Zingoni A, 2017. Predicting the head-area slopes of circular holes in water pipes. Procedia Engineering (186), 110 - 116.

Samir N, Kansoh R, Elbarki W, Fleifle A, 2017. Pressure control for minimizing leakage in water distribution systems. Alexandria Engineering Journal 56:601-612.

Schwaller J, Van Zyl JE, 2014. Modeling the Pressure-Leakage Response of Water Distribution Systems Based on individual leak behavior. Journal of Hydraulic Engineering 141(5), 04014089.

Ssozi EN, Reddy BD, Van Zyl JE, 2015. Numerical investigation of the influence of viscoelastic deformation on the pressure-leakage behavior of plastic pipe. Journal of Hydraulic Engineering 142(3), 04015057. 
Sturm R, Thornton J, 2005. Proactive Leakage Management Using District Metered Areas (DMA) and Pressure Management-Is It Applicable in North America. IWA Leakage 2005 Conference Proceedings, 1-13.

Thornton J, Lambert AO, 2007. Pressure Management Extends Infrastructure Life and Reduces Unnecessary Energy Costs. Proceedings of the IWA International Specialised Conference Water Loss 2007, 1-10.

Van Zyl JE, Clayton CRI, 2017. The effect of pressure on leakage in water distribution systems. Proceedings of the Institution of Civil Engineers - Water Management.

Van Zyl JE, Lambert AO, Collins R, 2017. Realistic Modeling of Leakage and Intrusion Flows through Leak Openings in Pipes. Journal of Hydraulic Engineering 143(9): 04017030.

Van Zyl JE, Malde R, 2017. Evaluating the pressure-leakage behaviour of leaks in water pipes. Journal of Water Supply Research and Technology - AQUA, 136, 66:287-299.

Walski T, Bezts W, Posluszny ET, Weir M, Whitman BE, 2006. Modeling leakage reduction through pressure control, Journal of American Water Works Association 98(4), 147-155.

Walski T, Whitman B, Baron M, Gerloff F, 2009. Pressure vs. flow relationship for pipe leaks. World Environmental and Water Resources Congress 2009, 342, 1-10.

Xu Q, Chen Q, Ma J, Blanckaert K, Wan Z, 2014. Water Saving and Energy Reduction through Pressure Management in Urban Water Distribution Networks. Water Resources Management 28 (11): 37153726. 